\section{El papel de los gobiernos locales en la lucha contra el flagelo del sida ${ }^{1}$}

Palabras clave: síndrome de inmunodeficiencia adquirida, virus de la inmunodeficiencia humana.

\footnotetext{
Basado en: Local government responses to HIV/AIDS: a handbook, elaborado por el Banco Mundial. Disponible en http://www. worldbank.org/urban/hivaids/localgovernments.htm. Acceso el 2 de diciembre de 2003.
}

La urbanización ha avanzado con una rapidez sin precedentes y se espera que para el año 2008 la mitad de la población mundial viva en áreas urbanas. Esto puede constituir una oportunidad para acelerar el desarrollo, facilitar el crecimiento económico sostenible y mejorar el estado de bienestar de la sociedad. Sin embargo, la infección por el virus de la inmunodeficiencia humana (VIH) y el sida pueden minar esta oportunidad, ya que mientras la epidemia diezma las fuerzas productivas, la demanda de servicios de salud aumenta, la capacidad de pago de la población afectada se reduce, la vulnerabilidad de las familias se acentúa y el número de pobres se incrementa.

De esta manera, la infección por VIH y el sida se han convertido en uno de los obstáculos más importantes para reducir la pobreza y lograr un mayor desarrollo. La Región de las Américas está muy afectada por esta pandemia, especialmente el Caribe, cuya prevalencia de infección por VIH y sida es la mayor en el mundo, a excepción de la del África subsahariana.

Muchos países que desarrollan en estos momentos programas nacionales contra el sida han visto profundamente afectada su capacidad de acción debido, precisamente, a los efectos de la propia enfermedad. En la mayor parte de los casos, los gobiernos locales no han recibido suficiente apoyo para enfrentar esta epidemia, a pesar de estar más cerca de las comunidades afectadas y, por lo tanto, en mejor posición para llevar las soluciones a la base. Sin embargo, incluso con un reducido apoyo (financiero o político), las agencias gubernamentals locales (AGL) pueden alcanzar importantes resultados en la lucha contra la infección por VIH y el sida mediante la incorporación de las medidas de respuesta contra este flagelo a los planes de trabajo de las municipalidades.

Precisamente, para ayudar a dar solución a esta compleja situación, el Banco Mundial acaba de sacar a la luz Respuestas de los gobiernos locales al VIH/sida: un manual (Local government responses to HIV/AIDS: a handbook). Este documento preparado en colaboración con la Iniciativa de la Alianza de Alcaldes por una Acción Comunitaria contra el Sida a Nivel Local (Alliance of Mayors Initiative for Community Action on AIDS at the Local Level, AMICAALL), Cities Alliance, el Programa de Gestión Ur- 
bana (Urban Management Programme) y el Programa de las Naciones Unidas para el Desarrollo (PNUD) - está dirigido a los funcionarios de las alcaldías y miembros de los órganos legislativos locales. Su objetivo es contribuir a fortalecer la capacidad de las instancias locales de gobierno de generar respuestas sostenibles y responsables para enfrentar el azote del VIH y el sida a nivel municipal.

Entre los temas abordados sobresale el dedicado al desarrollo de estrategias dirigidas a combatir el flagelo del VIH por parte de las autoridades de los gobiernos locales (AGL), en particular, lo relacionado con los riesgos que el VIH implica para su personal y su capacidad de brindar servicios y de apoyar el desarrollo de los programas en el entorno laboral.

\section{Los gobiernos locales y la lucha contra el sida}

Las áreas urbanas plantean oportunidades y retos específicos en la lucha contra el VIH y el sida, y las AGL deben participar en la respuesta a esta epidemia por varias razones:

1. Con frecuencia, las áreas urbanas son el centro de diseminación del VIH debido a la alta densidad y mezcla de la población, ya que son el núcleo de interconexión de los medios de transporte y tienen abundancia de grupos vulnerables, tales como los jóvenes, los trabajadores de paso y los trabajadores sexuales, entre otros.

2. Los sectores pobres de la población urbana están afectados desproporcionadamente por la infección por VIH y el sida, el alto costo de la atención de salud, y la pérdida de ingresos económicos debido a la enfermedad. Esto aumenta la vulnerabilidad de las familias pobres y se manifiesta más acentuadamente en aquellas que viven en asentamientos precarios, sin un sustento seguro, carentes de atención médica y de información.

3. El costo de la infección por VIH y el sida para las áreas urbanas va más allá de la pérdida de vidas humanas y del sufrimiento de los afectados. El incremento en la demanda de servicios de salud se conjuga con una menor capacidad para pagar los servicios municipales recibidos. La disminución de la fuerza de trabajo y de la mano de obra calificada, así como de los ingresos por impuestos, también impide que las municipalidades alcancen sus metas de desarrollo y pone en peligro su capacidad de garantizar los servicios fundamentales.
4. Las AGL son responsables del desarrollo social y económico de sus comunidades. El VIH y el sida pueden minar las inversiones que los gobiernos nacionales y locales, los donantes y otras agencias de financiamiento destinan a fortalecer el funcionamiento de los municipios, sus finanzas, los servicios locales que brindan (en particular a los pobres) y el desarrollo económico local.

Las AGL deben, por lo tanto, definir su respuesta al VIH y al sida dentro del contexto de sus responsabilidades.

\section{Qué pueden hacer las autoridades locales}

Los retos que imponen la infección por VIH y el sida en las áreas urbanas llevan a la necesidad de emprender acciones a escala local. Aunque las autoridades locales están más cerca de los afectados por el VIH y el sida y, por consiguiente, en mejores condiciones para llevar a cabo las intervenciones necesarias, las AGL solo pueden triunfar en su enfrentamiento con el VIH y el sida si trabajan en estrecha relación con todos los niveles de gobierno y otros factores locales de la sociedad civil que participan en la lucha contra el VIH y el sida en la comunidad.

Las AGL cumplen por lo general muchas funciones. Sin embargo, la implementación de respuestas de gran alcance contra el VIH y el sida no ha sido tradicionalmente una de sus actividades centrales. De hecho, la ventaja comparativa más evidente de las AGL puede ser su capacidad de fomentar un ambiente que facilite la coordinación, la dirección y la contratación de medidas contra el VIH y el sida, bien sean nuevas o de las ya existentes en la localidad.

Estudios recientes apuntan a que las estrategias preventivas más eficaces contra el VIH y el sida pueden estar muy estrechamente vinculadas con el grado de apertura y franqueza con el que se maneje la amenaza de la infección por VIH y el sida en las comunidades. Los líderes locales pueden dar (aun con recursos limitados) un gran impulso a la lucha contra la infección por VIH y el sida utilizando su posición para combatir el estigma que ambos implican y facilitando la discusión abierta en la comunidad acerca del impacto real e inmediato que pueden tener el VIH y el sida en los miembros de familia, amigos y compañeros de trabajo.

El éxito de la lucha contra el flagelo del VIH y el sida depende del esfuerzo de diferentes instancias. Las AGL deben garantizar el futuro de sus pueblos, ciudades y comunidades mediante acciones contra el VIH y el sida, mientras que los programas nacionales deben cumplir su mandato 
CUADRO 1. Condiciones que deben satisfacer las acciones emprendidas por las autoridades de los gobiernos locales (AGL) contra el VIH y el sida

- Ser coherentes con la política nacional contra el sida y orientarse hacia las necesidades locales

- Basarse en la comprensión de las realidades, normas y tendencias locales, en particular del impacto del VIH y el sida en la comunidad, en el funcionamiento municipal y en la existencia de recursos y posibilidades para responder al VIH y al sida. Deben prestar atención especial al riesgo particular que enfrentan las mujeres y los jóvenes

- Contar con el apoyo activo de los líderes de las AGL y grupos de trabajo compuestos por las AGL y los accionistas de la comunidad

- Agrupar a los diferentes sectores de la comunidad y reconocer que tanto el impacto del VIH y del sida como las acciones de respuesta requieren un enfoque multifactorial

- Evaluar integralmente la mejor manera de llevar a cabo la prevención, el tratamiento y la atención médica, y la mitigación del impacto

- Estar dirigidas tanto a lo interno (el personal de las AGL y sus familias) como a lo externo (la oferta y la coordinación de los servicios)

- Lograr la integración funcional de los programas y servicios relacionados con el $\mathrm{VIH}$ y el sida, tanto dentro de las AGL (especialmente la integración de los servicios de salud y bienestar social) como entre las AGL y las agencias de la comunidad que trabajan con el VIH y el sida (integración de esfuerzos de diferentes proveedores de servicios)

- Integrarse a los programas de desarrollo de las AGL en lugar de aislarse como un área independiente de intervención

- Aumentar la participación comunitaria en el planeamiento, diseño e implementación de los programas. Esto implica la necesidad de involucrar activamente en los procesos de consulta a las personas infectadas y afectadas por el VIH y el sida y a las organizaciones que las representan

- Comprometerse a tratar los aspectos relacionados con el estigma y la discriminación de las personas con VIH y sida, así como las implicaciones de género que plantea la epidemia

- Movilizar y coordinar los recursos, tanto dentro del entorno de las AGL (sociedad civil y comerciantes) como fuera de él (fuentes externas de financiamiento y apoyo)

- Basarse en el enfoque de "aprender sobre la marcha" mediante el empleo de sistemas de monitoreo y evaluación que fortalezcan las acciones emprendidas a lo largo del tiempo

de apoyar las respuestas locales sostenibles y responsables contra el VIH/sida y brindar su apoyo a las acciones de respuesta de los gobiernos locales.

Para que las respuestas de las AGL contra el VIH y el sida sean eficaces deben cumplir determinadas condiciones (cuadro 1).

El propósito de cualquier estrategia para combatir el VIH y el sida debe ser ofrecer un marco de trabajo que permita a las AGL enfrentar la amplia gama de problemas que impone esta epidemia en sus localidades. En ese marco de trabajo se deben identificar los objetivos de la estrategia, indicar cómo se lograrán estos objetivos e identificar a las personas y entidades que deben participar en la lucha contra este flagelo. Todo ello depende en gran medida de la elaboración e implementación de una estrategia interna coherente y responsable.

\section{Desarrollo de una estrategia interna}

Para desarrollar una estrategia interna de las AGL en torno al manejo de los portadores del VIH y los casos de sida en el marco de sus empleos se deben cumplir diferentes etapas:

Etapa 1. Establecer un subgrupo para elaborar una política específica que se aplique en los puestos de trabajo.

Etapa 2. Recolectar toda la información de base necesaria (esto puede abarcar las políticas nacionales sobre la infección por el VIH y el sida en los lugares de trabajo, las políticas elaboradas por los gobiernos locales, las evaluaciones realizadas sobre el impacto local y los presupuestos disponibles).

Etapa 3. Alcanzar un consenso acerca de los objetivos que se persiguen, los principios directivos y los elementos que debe contener la política propuesta.

Etapa 4. Elaborar un borrador de la política.

Epata 5. Realizar un amplio proceso de consultas en torno a la política propuesta y enriquecerla de acuerdo con los comentarios recibidos. (Entre los factores sociales que deben consultarse se encuentran las asociaciones laborales, los representantes de los sindicatos y las agrupaciones que pudieran brindar servicios y entrenamiento para implementar esta política).

Etapa 6. Desarrollar un plan para implementar la política acordada y hacerla ampliamente disponible a todo el personal del gobierno local.

Por su parte, las acciones de respuesta en las localidades deben cumplir con determinados estándares mínimos y satisfacer algunos principios importantes que no deben faltar en la política interna adoptada por las AGL para el marco laboral. En este sentido, los estándares utilizados en África del Sur pueden constituir una guía de estos estándares.

En el caso de la política se deben tener en cuenta los siguientes elementos esenciales:

- Prohibir la discriminación y prever acciones que impidan la discriminación de las personas por ser portadoras del VIH o padecer de sida

- Prohibir las pruebas para detectar el VIH sin autorización legal 
- Promover la búsqueda de asesoramiento especializado y las pruebas de laboratorio voluntarias

- Garantizar la confidencialidad del estatus de los empleados con relación al VIH

De igual manera, la estrategia interna que adopten las AGL en relación con el VIH y el sida debe satisfacer determinados estándares mínimos. Para ello, la experiencia sudafricana propone utilizar los siguientes criterios:

- Ofrecer programas de educación, información y prevención de la infección por VIH y el sida

- Estimular la franqueza de las personas con VIH o sida y su aceptación por parte de la sociedad

- Contemplar acciones para evaluar y prevenir el riesgo de exposición ocupacional al VIH

- Prever acciones que faciliten la compensación de los empleados infectados como resultado de accidentes laborales

- Asignar claramente las responsabilidades relacionadas con la infección por VIH y el sida

- Contemplar una estrategia de comunicación sobre el VIH y el sida

- Prever el monitoreo y la evaluación de la política establecida

- Tomar en cuenta las implicaciones de género en cada uno de los aspectos anteriores y prever su correcta aplicación en el entorno laboral

Estos estándares mínimos se entienden como elementos de base para desarrollar las políticas y estrategias relacionada con el VIH y el sida. Las políticas locales sobre el VIH y el sida deben, hasta donde lo permitan el presupuesto y las capacidades disponibles, tomar en cuenta las cuestiones relacionadas con la prevención, la atención médica y la mitigación de las dificultades provocadas por esta epidemia.

Además de orientar detalladamente a las AGL acerca de los principios y el proceso de elaboración y aplicación de políticas internas, en Respuestas de los gobiernos locales al VIH/sida: un manual se brinda una pormenorizada información —con ejemplos e instrumentos tales como encuestas, módulos y guía de procedimiento-que se debe tener en cuenta para evaluar el impacto del $\mathrm{VIH} /$ sida en la localidad e identificar los actores clave responsables de iniciar y coordinar la respuesta de las AGL ante esta amenaza. El manual también sirve de guía para implementar políticas y estrategias en las localidades; sugiere las vías para movilizar recursos, tanto nuevos como ya existentes; orienta acerca de cómo desarrollar relaciones productivas con las organizaciones de la sociedad civil; y propone sistemas de monitoreo, aprendizaje y evaluación.

Aunque se espera que cada órgano de gobierno local observe de manera creativa las indicaciones contenidas en este manual, el respaldo teórico y el enfoque práctico de su contenido garantizan que su aplicación fortalecerá la capacidad de respuesta de las AGL ante el flagelo del VIH y el sida.

\section{SYNOPSIS}

\section{The role of local governments in the fight against the scourge of AIDS}

The challenges imposed by HIV/AIDS in urban areas make it imperative to act at the local level. Local government agencies (LGAs) are closer to the victims of HIV/AIDS and are thus better able to undertake the needed actions. However, LGAs can succeed in the fight against HIV/AIDS only if they work closely with all levels of government and other local representatives of civil society that take part in the struggle against HIV/AIDS at the community level. In fact, the most obvious comparative advantage of LGAs may be their capacity for creating an atmosphere that is conducive to coordinating, directing, and undertaking local measures - both new and preexisting - against HIV/AIDS. Even with reduced support (financial or political), LGAs can achieve significant results in the fight against HIV/ AIDS by incorporating response measures against these conditions in the municipal agenda. It is precisely in order to help solve this complex situation that the World Bank has just published a book entitled Local Government Responses to HIV/AIDS: A Handbook. This text is intended for officials working for the mayor and members of local legislative bodies in charge of implementing sustainable and responsible measures against HIV/AIDS at the municipal level. Though it is hoped that each local government office will creatively follow the suggestions given in this manual, the theoretical framework and practical approach in it are a guarantee that applying them will lead to an improved ability to respond against HIV/AIDS on the part of local government agencies. 